\title{
Exploring Language Teachers' Perceptions of Cyclical Presentation of Materials in an EFL Context: A Grounded Theory
}

\author{
Seyyed Ali Ostovar-Namaghi ${ }^{1} \&$ Maryam Gholami ${ }^{1}$ \\ ${ }^{1}$ Shahrood University of Technology, Iran \\ Correspondence: Seyyed Ali Ostovar-Namaghi, Shahrood University of Technology, Iran. E-mail: \\ saostovarnamaghi@yahoo.com
}

\author{
Received: August 5, 2017 Accepted: February 12, 2018 Online Published: February 15, 2018 \\ doi: 10.5539/elt.v11n3p60 URL: http://doi.org/10.5539/elt.v11n3p60
}

\begin{abstract}
Numerous studies have verified the effect of cyclical presentation of materials on learners' language proficiency and achievement. However, there is a dearth of research exploring language teachers' perceptions of cyclical approach. Since teachers' perceptions may catalyze or nullify the effect of this approach, this study aims at exploring experienced language teachers' perceptions through the reformulated grounded theory (Stauss \& Corbin, 1990). Using non-probability sampling procedures, fifteen experienced teachers, both male and female, were selected from the population of language teaches teaching in junior high schools of Shahrood, a major city in Semnan province, Iran. Iterative data collection and analysis and the constant comparative techniques yielded "Merits of Cyclical Presentation" and "Suggestions for Practice" as the two main categories, each subsuming some propositions. Among other things, the emerged propositions revealed that cyclical presentation: helps students internalize materials; reduces students' level of stress and tension; serves a remedial function; and increases students' motivation. Since the syllabus imposed by central agencies is linear in nature, participants suggested down-to-earth techniques to modify the syllabus and pave the way for cyclical presentation of materials where possible. The findings have clear implications for language teachers, syllabus designers and language learners.
\end{abstract}

Keywords: cyclical presentation, teachers' perceptions, linear presentation, data-driven

\section{Introduction}

A review of empirical findings clearly shows that cyclical presentation of materials is far more effective than the linear presentation; nonetheless, central agencies and commercial curriculum developers and syllabus designers impose their linearly-organized materials on language classes in different contexts. Knowing that teachers exercise their agency and modify the linear syllabus if they positively perceive cyclical presentation, this study was conducted to explore teachers' perceptions of cyclical approach. Exploring and conceptualizing experienced teachers' perceptions of the cyclical approach are significant to the field because these perceptions nullify or catalyze the effect of the syllabus. That is, if they positively perceive cyclical presentation of materials, they modify linear syllabi to make way for cyclical exposure to the new language forms, functions, topics and tasks. Conversely, if they have a negative attitude towards cyclical presentation, they modify the materials in alignment with their professional beliefs. Although there are numerous theory-driven studies which test the comparative effect of cyclical and linear presentation of materials, there is a dearth of knowledge as to language teachers' perceptions of the cyclical approach. The findings of studies that explore and conceptualize teachers' perceptions of this approach complement the findings of the hypothetico-deductive studies.

\subsection{Review of the Related Literature}

A linear syllabus attempts to extend learners' knowledge through adding new blocks of information. As Howatt (1974) states, "new points are strung along in a line and each one is, so to speak, sucked dry before moving on to the next one and the pupil must make an enormous effort to assimilate each new point the first time it appears because when he turns the page he will go on to something else" (Howatt, 1974). On the other hand, a spiral syllabus is one in which the learners are challenged with the repetitive revisiting of topics, subjects or themes all over the development. A spiral curriculum is not simply the repetition of a topic taught, it also involves the deepening of it. Bruner (1960) believes that any body of knowledge is presented spirally if it is continually revisited and reexamined to deepen the pupils' understanding. This notion of revisiting and reexamining 
fundamental ideas over time is what has become known as a spiral curriculum.

Many scholars believe that language acquisition process would benefit from a cyclical syllabus (Dowding, 1993; Howatt, 1974; Kabara, 1972; Skehan, 1996; Veselinovska, Gudeva, \& Djokic, 2011). Skehan (1996) believes that language acquisition process is much more of an organic, natural process that would benefit from a recycling syllabus, although you can hardly ever see cyclically designed syllabi and lessons. Similarly, Howatt (1974) believes that following cyclical approach to teaching grammar is preferable as it leads to the gradual acquisition of grammar that is in harmony with what is known about interlanguage development. In a similar direction, Veselinovska, Gudeva, and Djokic (2011) believe that creating new circumstances leads to new learning experiences which educate more autonomous, self-conscious, creative, and active language learners. Similarly Dowding (1993) and Kabara (1972) believe that spiral curriculum leads to the reinforcement for what is already known as new knowledge and skills are introduced in subsequent lessons. The main reason for such reinforcement is the linkage between the lessons.

In general education, Veladat and Mohammadi (2011) found that compared with traditional methods, spiral learning teaching method had a significantly higher difference in learning performance of second grade elementary school students in a biology course. Similarly, Kang (2016) addressed how the available instructional time might be optimally utilized via the scheduling of review and practice. He found that spaced practice was a more cost-effective way to improve the effectiveness and efficiency of learning. Similarly, Hillary et al. (2003) aimed at examining whether persons with moderate and severe traumatic brain injury would benefit from the spaced effect. and found that employing the spacing effect during learning can significantly improve subsequent recall and recognition performance in persons with.

In language education some scholars (e.g., Baleghizadeh \& Asadi, 2013; Mojavezi, 2013; Ahmadian \& Tavakoli, 2011) tested the effect of task repetition and task recycling on learners' fluency and proficiency. Baleghzadeh and Asadi (2013) found a significant difference between task repetition and task recycling on oral performance. In a similar study, Mojavezi (2013) found that task repetition has a significant efect on the complexity, accuracy, and fluency of L2 learners with different levels of proficiency. Similarly, Takimoto (2012) tested the relative effectiveness of repeating the same task and the same type of task on recognizing and producing English by EFL learners and found that the former was significantly more effective than the latter.

As the review clearly shows, the studies conducted on spiral presentation of teaching materials are all experimental and correlational in nature. Despite the importance of language teachers' perceptions of the cyclical approach and their awareness of the strengths and weaknesses of this mode of presenting materials, none of the reviewed studies has tried to gain an insider's view of this approach to materials development.

\subsection{Purpose of the Study}

While the cyclical presentation of materials may be inherently more effective than linear the traditional approach the organizes and presents materials in a linear fashion, language teachers' taught processes and perceptions may catalyze or nullify its potential; hence, this study aims at exploring experienced teachers who are willing to share their perspectives, perceptions and experiences of the cyclical approach to materials and methods of language teaching. To elicit theoretically relevant data, experienced teachers answered the grand tour question, "What are your perceptions of the merits and demerits of the cyclical approach and your suggestions for the effective implementation of this approach?" Having sought some initial data from interested participants, we analyzed them not only to develop transient themes but also to develop more refined and directed questions which helped us collect and analyze theoretically relevant perspectives on cyclical approach.

\section{Methodology}

Rather than following the classic grounded theory or a constructivist approach, this study follows the principles and practices of reformulated grounded theory (Strauss \& Corbin, 1990). The data were collected through cyclical interviews and analyzed based on a series of open, axial, and selective coding techniques coupled with the use of constant comparative technique.

\subsection{Sampling Procedure and Participants}

In line with grounded theory which rejects probability sampling, in this study sampling was theoretical in that sampling was determined by the emerging theory. along these lines, 15 Iranian EFL teachers teaching in public high schools of Shahrood, a major city in Semnan province Iran. Having sought the perspectives of 15 participants, both male and female edperienced language teachers, we reached a point of theoretical saturation, where teachers' perspectives on cyclical approach seemed redundant. 


\subsection{Data Collection and Analysis}

Teachers' perspectives on the cyclical approach were collected through open-ended interviews. First, we ensured the participants that their perspectives will remain anonymous and the final will report nothing but pseudonyms. Second, we sought their participants' informed consent. Third, we posed the grand tour question to collect some preliminary data for analysis. Fourth, as suggested by Strauss and Corbin (1998) we followed a funnel-like approach by asking more refined questions which aimed at deepening our understanding of the participants' perspectives. Not only were the participants' perspectives audio-taped, memos were also written throughout the process of data collection to record our ideas, assumptions, and feelings towards teachers' perspectives on cyclical presentation of materials.

Following Strauss and Corbin (1998), during the first stage of coding, i.e., open coding, the transcribed data were broken down into units of meaning, and then labeled them with words and phrases that abstracted and conceptualized the participants' perspectives. During axial coding, we tried to deepen our understanding of the participants' perspectives answering how, why, when and where questions. Finally, through selective coding we tried to find the core category which weaved the emerged themes and categories into an "an explanatory whole" (Strauss \& Corbin, 1998). The iterative process of data collection and analysis and the constant comparison of the emerged themes with the participants' perspective continued until we reached a point of theoretical saturation.

\subsection{Establishing Trustworthiness of the Study}

To establish the trustworthiness of the emerged themes and categories, we made use of what is commonly known as member checking strategy. More specifically, after transcribing the recorded interviews, we send the original transcripts back to the participants to check whether they reflected what they meant or not. This gave them a chance to correct any misinterpretations in transcribing the data. Moreover, transient concepts and categories together with the final conceptualization were shown to the participants for verification and any possible modifications. What follows reflects the findings as verified by the participants.

\section{Findings}

Iterative data collection and analysis of language teachers' perspectives on cyclical presentation of materials revealed the advantages of this approach together with techniques of implementing it. Among other things, analysis revealed that cyclical presentation of materials: helps students internalize the materials; reduces their tension and stress; increases students' self-esteem; remedies probable weaknesses in learning; and increases students' motivation. Apart from revealing the merits of cyclical approach, analysis revealed some techniques which are conducive to successful implementation of this approach to materials development and presentation.

\subsection{Merits of Cyclical Approach}

Compared with theory-driven studies that aim at hypothesis testing, this studies yielded a set of propositions which reflect the merits of cyclical presentation of materials over the traditional approach which presents materials in a linear fashion. What follows aims at presenting each of these propositions and grounding them in the participants' perspectives.

\subsection{Cyclical Presentation Helps Students Internalize Materials}

Language learners have two main challenges: understanding the materials, and internalizing them. As the participants believed, the former depends on systematic presentation of materials while the latter depends on repeated exposure to the same materials at varying levels of complexity. Supporting this view, one of the participants states:

Students are highly dependent on their textbooks and it is not possible for them to practice English out of the classroom. Hence, they're likely to forget their language knowledge very soon because they do not have any speaking and writing practice outside the classroom. This problem can be resolved if materials are presented cyclically. When materials are diffused throughout the text, rather than presented once, they internalize them more effectively.

While in ESL situations learners find a chance to use what they have learned outside the classroom, in EFL situations such as Iran, where English has no social function, students forget what they have learned because of lack of use. Participants believed that cyclical presentation of materials in the textbook can remedy this educational ill effectively. Nonetheless, the textbooks written for junior high schools ignore this fact. Addressing this problem, one of the participants explains:

In grades seven and eight, each lesson is loaded with new words. Instead of using the words students have 
previously learned, each lesson introduces some new words. Since in each lesson students learn some new words without having a chance to internalize them, they forget them very soon after they learned them. I think students can internalize the words they learn if they reappear systematically. This gives them a chance not only to use what they have already learned but to learn new words.

\subsection{Cyclical Presentation Reduces Learners' Tension and Stress}

The next sub-category of the advantages of the cyclical syllabus is the reduction of students' stress. Learners are afraid of failing to learn. The students should be warmed up by discussing the previously taught materials in order to feel free and relax towards learning the new lesson. In this manner, they build a bridge between their old and new knowledge through revising and reviewing the earlier learned materials. In this regard, one of the teachers stated:

I believe that cyclical approach reduces learners' level of stress because it uses known materials to introduce new materials. Since students connect new information to what they already know, they understand and enjoy the materials. On the other hand, when each lesson presents new materials without any reference to previously learned materials, students are stressed out since they find mechanical repletion as the only mode of learning. I believe cyclical approach encourages meaningful learning and as such minimizes stress while the linear presentation of materials encourages rote learning and maximizes stress.

In addition to being conducive to meaningful learning which is a determining factor in reducing stress, repeated exposure to the teaching materials not only clarifies any ambiguities but also increases students' self-confidence when they use what they have learned in understanding new subjects or points. And as the participants stated, it is this decrease in ambiguity and the increase in self-confidence that reduces their stress and tension. Supporting this perspective, one of the participants states:

When you face materials for which you have no background knowledge you are stressed out because learning depends on activating your schemata. Conversely, when the lesson is familiar because what you have learned reappear in the new materials, not only you understand the materials more deeply but also forget the fear of failing to learn. While the very act on understating new martials, failing to understand the materials for which you have not background knowledge decreases your confidence and increases your level of tension and stress.

\subsection{Cyclical Presentation of Materials Serves a Remedial Function}

Teaching is not learning. That is, there are always weaknesses in teaching and learning; hence, in addition to presenting the materials teachers should make sure the students have a deep understanding of the materials. However, since the time allocated to language education in public high schools is not sufficient, teachers see their main concern as covering the textbook in time for the mid-term and final exams and as such leave no time to remedy weaknesses in teaching and learning. Cyclical presentation of materials solves this problem since understanding new materials is contingent upon understanding previous materials. Participants believed that teachers take any possible difficulty in learning the new lesson as a sign of failure in learning the previous lesson and as such do their best to review the materials. Focusing on the remedial function of cyclical approach, one of the participants explains:

I believe when materials are presented linearly, I see reviewing the previous materials and even learners' understanding of the previously learned materials as redundant. That is, since understanding the new materials does not depend on learners' understanding the previously presented materials, I start the new lesson without any remedial teaching. But when understanding the new lesson depends on understanding the previous materials, prior to teaching new materials I have to check students' mastery over previous lessons and review them prior to teaching the new lesson. In junior high schools materials do not recur and as such I can start the new lesson without reviewing the previously lessons.

In our education system, teachers teach $\mathrm{A}, \mathrm{B}, \mathrm{C}, \ldots$ linearly. Since $\mathrm{A}, \mathrm{B}$, and $\mathrm{C}$ are independent, teachers take remedial teaching as a soft option. However, if materials are presented cyclically, learning B builds upon learners' understanding of A. Similarly, learning $\mathrm{C}$ is interdependent on learning A and B. Under such circumstances, teachers take remedial teaching as an inseparable part of the teaching process since learning and teaching become increasingly difficult without mastery over previously taught materials. Reiterating the necessity of remedial teaching in the cyclical syllabus, one of the participants states:

To me, language education in public high schools is a waste of time and resources since after a two-week interval, one can see very few traces of learning. Even traditionally, teaching is a three-step process: presenting materials, helping students consolidate their learning through practice, and finally, encouraging learners to produce and understand massages by using what they have learned. Since learning a new lesson does not 
depend on learning the previous lesson, teachers see remedial teaching as a waste of time and see their task as presenting the materials without paying any attention to practice and production. I believe cyclical presentation of materials not only improves this educational ill but also improves teaching and learning.

\subsection{Cyclical Presentation Motivates Students to Learn}

Having learned something, learners look for situations in which they can use what they have learned. When students see that previous lessons help them understand new materials, they are motivated to learn the new lesson because not only does it expose them to new materials but also gives them a chance to use what they have learned. Having no difficulty in learning new materials and having a chance to use what they have previously learned motivates them and involved them in the process of learning. Explain the motivational function of the cyclical approach, one of the participants explains:

When the students see that they know something about what the teacher is writing on the board and they can answer the teachers' questions, they are motivated to learn and participate in classroom activities. On the contrary, when the new lesson does not build on previous materials, learners find it difficult to understand and this demotivates them. Since English has no social functions, learners are not motivated to learn. Cyclical presentation of materials is motivating in itself because it paves the way for using what they have already learned rather than learn new materials without being able to use them.

Recurring materials are motivating since it paves the way for self-evaluation, self-monitoring and give students a sense of progress. Conversely, linear presentation of materials deprives students of such feelings since they leave no room for using previously acquired materials. Believing that cyclical approach motivates students by giving them a sense of progress, one of the participants states:

By applying cyclical syllabus, students can see their progress in learning. They can see that they are able to use what they have learned at least in transactional dialogues, i.e., exchanging and evaluating the information they learned and in making sense of the new materials. Feeling competent to use previously learned materials in making sense of new materials is a sign of progress and inherently motivating.

\section{Suggestions for Practice}

Participants believed that instead of presenting a topic once and for all, materials can split each topic into several segments and present each segment in a separate lesson with varied levels of difficulty, complexity and information. Elaborating this technique, one of the participants explains:

Suppose, the materials aim at introducing family members. In one lesson, they can introduce nuclear family, in another lesson they can extend the topic by presenting extended family, and still in another present their occupations and in another they can introduce their likes and dislikes. In this way, each lesson builds on the previous lesson by adding more relevant information. Cyclical exposure to the same topic not only builds their background knowledge but also gives students a chance to use it in making sense of new information.

Providing students with topic-related readings is considered to be effective as it causes students review most of the acquired vocabularies. That is, instead of presenting the whole topic in one lesson, materials can present part of the topic and then successively go deeper down. Explaining the importance of cyclical exposure to the same topic, one of the participants explains:

Why should we present food and drinks in one lesson? I believe we can break it into separate parts such as food and drinks, food pyramid, and healthy diet and present each part in a separate lesson. This gives the students the opportunity to use what they have learned in subsequent lessons and internalize not only the pertinent words and phrases but also the content knowledge.

The participants further believed that we should not expect students to learn a specific function in one lesson. To master a social function of the target language, that function should recur systematically rather than be presented in one lesson. While it may be sufficient to master one or two forms that expresses that function, they are not sufficient to understand that function because participants believed that comprehension of language functions far exceeds its production. One of the participants explains the complexity of understanding social functions as follows:

Commercial textbooks present social functions very superficially by exposing students to some fixed phrases. For instance, to present the function, 'saying goodbye' they present two or three fixed phrases. These phrases may be sufficient for production since they can decide what form to use but they are not enough for comprehension because we cannot predict what forms others will choose to say goodbye. For instance, suppose students know fixed phrases such as 'goodbye' 'take care' and 'see you later'. For sure, they will have difficulty understanding 
words and phrases such as 'cheerio', 'farewell', 'so long', 'catch you later', 'good night' and so on and so forth. Since presenting all these forms in one lesson is boring, they can be introduced cyclically.

Vocabulary can be no exception. Participants believe that one-shot presentation of words in traditional syllabuses confuses learners when they face a new use of the word. One of the participants explains how the way the word do is presented in some textbooks may confuse students when they encounter other uses of the word.

Textbooks expose students to the generic use of the word 'do' through adjacency pairs such as, "What are you doing?" "I'm doing my homework" and ignore its other uses. Such a shallow presentation of the word 'do' doesn't help students in understanding phrases such as 'That will not do", 'do the dishes', 'do one's hair' and 'do the cleaning'. I believe reintroducing the word 'do' in separate lessons will clarify its communicative utility.

\section{Discussion and Implications}

One of the propositions revealed that cyclical presentation of materials help students internalize materials. This finding confirms Bruner's (1960) argument that returning again and again to the basic concepts which cyclically become more complex help students understand them more fully. It is also consistent with Dowding (1993) and Kabara (1972) who found that cyclical approach leads to the reinforcement of what is already known as new knowledge and skills are introduced in subsequent lessons. Furthermore, participants believed that cyclicality prevents forgetting. This finding is in accordance with the first feature of spiral curriculum introduced by Harden (1999). Likewise, the findings revealed cyclical presentation reduces students' level of stress by improving their mastery over the materials. This findings conforms the results Gass et al. (1999) who found that task repetition resulted in improvement in overall proficiency, selected morphosyntax, and lexical sophistication.

While some of the emerged propositions which reflect the merits of the cyclical approach verify previous findings, some of the findings have no precedent in previous studies. For instance, among other things, conceptualization of the participants' perceptions of the cyclical presentation of materials revealed that this approach not only serves a remedial function, it also reduces students' level of stress by improving their self-confidence and providing then with a chance to use what they have learned in making sense of new materials. Taking the merits of cyclical presentation of materials into account, it is suggested that:

- Language teachers alleviate the shortcomings of linear syllabuses by readdressing the same topics, functions and task repeatedly rather than presenting them the way prescribed by the syllabus;

- Syllabus designers shift away from the linear presentation and organization of the materials towards the cyclical approach to provide EFL learners with opportunities not only to learn and deepen their depth of processing but also to use what they have learned and uncover the communicative utility of the materials through actual use;

- Language learners shift their focus away from learning forms and functions linearly towards cyclical deepening of their awareness of each form and function and using it in various contexts prior to learning new forms and functions.

\section{References}

Ahmadian, M. J., \& Tavakoli, M. (2011). The effects of simultaneous use of careful online planning and task repetition on accuracy, complexity, and fluency in EFL learners' oral production. Language Teaching Research, 15(1), 23-49.

Ausubel, D. P., \& Youssef, M. (1965). The effect of spaced repetition on meaningful retention. The Journal of General Psychology, 73(1), 147-150. https://doi.org/10.1080/00221309.1965.9711263

Baddeley, A. D., \& Longman, D. J. A. (1978). The influence of length and frequency of training session on the rate of learning to type. Ergonomics, 21(8), 627-635. https://doi.org/10.1080/00140137808931764

Baleghizadeh, S., \& Asadi, R. (2013). The effect of task repetition and task recycling on EFL learners' oral performance. Issues in Language Teaching, 2(2), 137-163.

Bruner, J. S. (1960). The process of education. Cambridge MA, Harvard University Press.

Carroll, J. B. (1973). Some suggestions from a psycholinguist. TESOL Quarterly, 7(4), 355-367. https://doi.org/10.2307/3585867

Charmaz, K. (2000). Grounded theory. Objectivist and constructivist methods. In N. K. Lincoln, \& Y. S. Denzin (Eds.), Handbook of qualitative research, 2 nd edition (pp. 509-535). Thousand Oaks: Sage.

Dowding, T. J. (1993). The application of a spiral curriculum model to technical training curricula. Educational Technology, 33(7), 18-28. 
Gass, S., Mackey, A., Alvarez - Torres, M. J., \& Fernandez - Garcia, M. (1999). The effects of task repetition on linguistic output. Language Learning, 49(4), 549-581. https://doi.org/10.1111/0023-8333.00102

Harden, R. M. (1999). What is a spiral curriculum? Medical Teacher, 21(2), 141-143. https://doi.org/10.1080/01421599979752

Hillary, F., Schultheis, M. T., Challis, B. H., Carnivale, G., Galski, T., \& DeLuca, J. (2003). Spacing of repetition improves learning and memory in moderate to severe TBI. Journal of Clinical and Experimental Neuropsychology, 25(1), 49-58. https://doi.org/10.1076/jcen.25.1.49.13631

Howatt, A. (1974). The background to course design. The Edinburgh Course in Applied Linguistics, 3, 1-23.

Kabara, J. J. (1972). Spiral curriculum. Journal of Medical Education, 47, 314-316. https://doi.org/10.1097/00001888-197204000-00019

Kang, S. H. (2016). Spaced repetition promotes efficient and effective learning: Policy implications for instruction. Policy Insights from the Behavioral and Brain Sciences, 3(1), 12-19. https://doi.org/10.1177/2372732215624708

Lincoln, Y. S., \& Guba, E. G. (1985). Naturalistic inquiry. Beverly Hills, CA: Sage.

Lynch, T., \& Maclean, J. (2000). Exploring the benefits of task repetition and recycling for classroom language learning. Language Teaching Research, 4(3), 221-250. https://doi.org/10.1177/136216880000400303

Miles, M. B., \& Huberman, A. M. (1984). Qualitative data analysis, a sourcebook of new methods. Newbury Park, CA: Sage.

Mojavezi, A. (2013). The relationship between task repetition and language proficiency. Applied Research on English Language, 3(1), 29-40.

Mukundan, J., \& Aziz, A. (2009). Loading and distribution of the 2000 high frequency words in Malaysian English language textbooks for Form 1 to Form 5. Pertanika Journal of Social Sciences \& Humanities, 17(2), 141-152.

Onwuegbuzie, A. J., \& Leech, N. L. (2007). Validity and qualitative research: An oxymoron? Quality \& Quantity: International Journal of Methodology, 41, 233-249.

Shea, C. H., Lai, Q., Black, C., \& Park, J. H. (2000). Spacing practice sessions across days benefits the learning $\begin{array}{lllll}\text { of motor skills. Human Movement } & \text { Science, } & \text { 19(5), }\end{array}$ https://doi.org/10.1016/S0167-9457(00)00021-X

Skehan, P. (1996). Second language acquisition research and task-based instruction. In J. Willis, \& D. Willis (Eds.), Challenge and change in language teaching (pp. 17-30). Oxford: Heinemann.

Skehan, P. (1998). A cognitive approach to language learning. Oxford: Oxford University Press.

Strauss, A. L. (1987). Qualitative analysis for social scientists. New York: Cambridge University Press. https://doi.org/10.1017/CBO9780511557842

Strauss, A., \& Corbin, J. (1990). Basics of qualitative research: Grounded theory procedures and techniques. Thousand Oaks, CA: Sage Publications.

Strauss, A., \& Corbin, J. (1998). Grounded theory methodology: An overview. In N. Denzin, \& Y. Lincoln (Eds.), Strategies of qualitative inquiry. (pp. 158-183). Thousand Oaks, CA: Sage.

Takimoto, M. (2012). Assessing the effects of identical task repetition and task-type repetition on learners' recognition and production of second language request downgrades. Intercultural Pragmatics, 9(1), 71-96. https://doi.org/10.1515/ip-2012-0004

Veladat, F., \& Mohammadi, F. (2011). Spiral learning teaching method: Stair stepped to promote learning. Procedia-Social and Behavioral Sciences, 29, 1115-1122. https://doi.org/10.1016/j.sbspro.2011.11.345

Veselinovska, S. S., Gudeva, L. K., \& Djokic, M. (2011). The effect of teaching methods on cognitive achievement in biology studying. Procedia-Social and Behavioral Sciences, 15, 2521-2527. https://doi.org/10.1016/j.sbspro.2011.04.138

\section{Copyrights}

Copyright for this article is retained by the author(s), with first publication rights granted to the journal.

This is an open-access article distributed under the terms and conditions of the Creative Commons Attribution license (http://creativecommons.org/licenses/by/4.0/). 